\title{
Investigation the Opportunity of BIM with Agile Management Approach in Iraqi Construction Projects
}

\author{
Ghassan A. Ahmed ${ }^{1, a^{*}}$ and Meervat R. Altaie ${ }^{1, b}$ \\ ${ }^{1}$ Civil Engineering Department, College of Engineering, University of Baghdad, Baghdad, Iraq. \\ ag.ahmed1101@,coeng.uobaghdad.edu.iq, bmeervat.r@coeng.uobaghdad.edu.iq,
}

\begin{abstract}
The construction industry in Iraq suffers from many problems, perhaps the most important of which is the delay in time and the increase in costs. Therefore, it was necessary to try to adopt a new methodology that would help in overcoming these problems. It was suggested to combine building information modeling with the agile management approach because this technique and methodology is modern and helps in reducing time and cost and improving quality. This paper aims to know the status of using Building Information Modeling (BIM) and Agile Project management (APM) in Iraq and to shed light on the merging of this integration, explaining the benefits, difficulties, and workflow practices, finding the most influencing factors on the time, cost and quality of the project. For a comprehensive understanding, the literature was reviewed for each of BIM and Agile separately, and an initial field survey was conducted to diagnose the factors of greatest importance, and a second field survey was conducted to know the effect of the factors identified from the initial questionnaire on time, cost and quality. The results indicated the weak use of BIM in Iraq, where the non-use rate reached more than $60 \%$ and the rate may reach $75 \%$. The agile methodology from the field survey sample is not used in this paper. The benefits that have been presented deserve to be overcome.
\end{abstract}

Keywords: Building Information Modeling (BIM); Agile Project management (APM); Traditional Project Management (TPM); Project Management Institute (PMI).

\section{Introduction}

Building Information Modeling (BIM) has been developed in recent years in the construction industry with an increase in the demands of this industry. BIM is a smart model based on a process that prepares insight to help professionals manage, plan, design, and build buildings. Most of BIM use revolves around design issues, lack of coordination in design and solving these problems, concurrency, and building performance and quality. The application of BIM in the construction industry demonstrates its use for feasibility studies, logistics, conceptual design, detailed design, coordination, detailing, estimation, construction planning, operations, and many other joint construction activities. BIM provides a level of a solution in terms of design optimization but can take into account BIM's ability in business management including project management, cost management, and facility management and on this basis, this paper focuses on the integration between agile project management and building information modeling [1].

\section{BIM}

In this section a review of the literature on BIM.

BIM and Management. The design team is closest to BIM, and the project management may not be involved in drafting the model, but it has an activity and a critical role in ensuring the essential elements needed for an effective and good project are in place. After the design phase, project managers need to consider the procedures and resources used during their project life cycle and the need to handle assets from start to finish. In order to optimize its benefits, management must also recognize, interview, supply, and verify BIM data. They must use model knowledge and modern business approaches to support new building technology, planning, costing, efficiency, coordination, 
development, sequencing, and services, to name only a few. For the Construction Manager to be able to handle this increased position, he needs to consider new instruments, processes, and skills [2]. BIM enables managers to easily trade information between the design team (architects, surveyors, civil and construction engineers, etc.) to the main contractor and sub-contractors and then to the owner/operator; This reduces losses and provides more understandable information to the owner. The management's use of BIM models is challenging and an attempt to reduce expenses and resolve disputes between departments in a short time.

BIM Benefits. The benefits of BIM can be summarized in the list below:

- BIM can be used with Cloud technology - it's the delivery of different services through the Internet. These resources include tools and applications like data storage, servers, databases, networking, and software - for portable access.

- Generate detailed and consistent 2D drawings at all design levels.

- Working with the BIM model gives ease to users and gives the ability to explore the building in three dimensions and ease of understanding information instead of wasting time looking at a lot of two-dimensional graphics in traditional methods

- Workers can work from anywhere and are still actively involved in the collaboration process.

- Help in detecting risks early, avoiding incidents, and communicating danger.

- Cost savings for the whole project.

- Low-level automatic corrections in the making of design adjustments.

- Improved facilities management and service.

- Power and sustainability improvements.

- Preconstruction recognition of contradictions in the model.

- Major technological advancements about conventional CAD, providing more knowledge and interoperability [3].

- BIM offers more rapid criteria for standardization by trade standards for enhanced cooperation.

- 3D geometry promotes pre-manufacturing trust that allows for higher efficiency, reduced labor, and speeded schedules.

- 4D planning and planning optimized via integrated tools.

- Visual inspection through virtual design and development, the purpose to design, and the exchange of information improve customer satisfaction levels.

- Enhances the management of knowledge through the capture and production in the design process of more comprehensive details.

- Productivity increased because the information was quickly retrieved.

- Building coordination reduces building time and removes change orders.

- Costs and risks are minimized for the contractor and subcontractor.

- Entry and connection of essential information such as suppliers of particular products, the position of information, and quantities needed for tendering and estimation [3].

BIM Planning Execution (BPE). Table 1 shows the uses of BIM to communicate the project phases, as it shows the tools used for each stage to communicate with the BIM model in order to achieve the goals in the offices, whether consulting or contracting, and that is written in the agreed contract clauses from the previous clear actions and attention must be paid to each stage because it represents an essential part in its stages It requires cost and time, and we will delve into each stage with clarification and explanation according to their order of needs [4]. 
Table 1. Using of BIM.

\begin{tabular}{|c|c|c|}
\hline Plan & Design & Operation \\
\hline Programming & Design Authoring & Building Maintenance Scheduling \\
\hline Site Analysis & Design Reviews & Asset Management \\
\hline & 3D Coordination & \\
\hline & Structural Analysis & \\
\hline & Lighting Analysis & \\
\hline & Energy Analysis & \\
\hline & Code Validation & Phase Planning (4D) \\
\hline \multicolumn{3}{|c|}{ Cost Estimation (5D) } \\
\hline \multicolumn{2}{|c|}{ Existing Conditions Modeling } \\
\hline
\end{tabular}

BIM Team. Creating a successful team can produce and achieve the desired goal, such as creating a model for a building that requires great effort. The main purpose of cooperative work is to standardize work methods and mechanisms and exchange information between different parties (designer, contractor, etc.) during work stages [5]. In order to form a work team, the following must be observed:

- The team should be aware of its duties and the sequence of work steps.

- The team gets a common vision of the work outcome.

- The team needs a time plan for the project as a whole as well as for each stage separately.

- Dividing work groups and duties into precise tasks that require knowing the capabilities of each member of the working group.

- Individuals receive adequate training and experience to meet business challenges

- The factors that maintain the work team must be achieved (appropriate salaries, good treatment, provision of equipment and programs appropriate to the workload).

- Standardization of terms used for the exchange of data and information (language, the concept of each term, a suitable method for naming different files ... etc.)

- Holding periodic meetings to coordinate between the project parties such as (reviewing the schedule, solving regular problems, etc.)

- Implementing an effective system to make the documentary cycle for the exchange of documents for the project effective, as well as creating electronic libraries for the rapid recovery of various types of documents (library of elements, tools, programs, and auxiliary programs, etc.) [5].

Division of the work team. The regular projects team consists of:

1) BIM Manager

2) Coordinators

3) Modelers

Either in the case of large projects or those that contain more than one building or are implemented in more than one company (specialized branches), the work team may increase according to the project need: For example, if more than one company is working on the same project, but in different specializations (architectural, electrical, mechanical, construction, etc.), then we will find for each BIM Chief that works in coordination with the BIM Manager. Either if the project consists of more than one building and every building is being worked on in a different company and every building contains all the works (architectural, electromechanical, structural ... etc) then here it is necessary to have (BIM Champion) - A designated individual who represents the key to driving the implementation of BIM strategy across the organization - or (BIM Specialist). The more complex the work, the greater the need to distribute roles and jobs to more individuals. For example, in huge building complexes, we may need a BIM Chief to assist the Deputy Director of BIM Champion (who is thus an assistant to the BIM Manager) [3]. 


\section{Agile Project management}

In this section a review of the literature on APM.

Why use Agile Project Management? One of the most important challenges to managing the cost, scope, and time of projects is the business needs and ever-changing requirements during the project phases in addition to the complexity and interconnectedness of the current commercial operations as they have increased at present from previous times and more complex organizational structures are being addressed and improved for projects that include complex suppliers consisting of alliances with strategic vendors, outsourcing and different types of competitors, partnerships and clients. In order to meet the needs of market completion and customer satisfaction, the challenges mentioned emphasizing the need for a flexible and adaptive approach to delivering projects, products, and services faster. The TPM approach prepared to meet these demands in all situations through the development and increasing adoption of APM. Lean management techniques will be used in $80 \%$ of all software development projects according to PMI Research has shown that the use of Agile has tripled. Such enhancements will lead companies to many benefits by cost savings, fast turnaround time, and improved loyalty and retention of consumers and customers [6].

How Agile Works? (Adoption of scrum processes). There are several different agile faces there. The determination is up to the community to come up with the right project process. Each protocol generally follows a brief life cycle, which repeats itself after each iteration. This research relies on Scrum. Scrum projects are broken down into short iterations (1-3 weeks) called sprints. The lifecycle of each sprint includes. Figure 1 shows the sprint lifecycle [7].

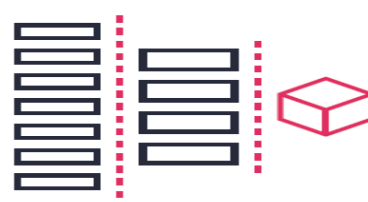

1. PLANNING

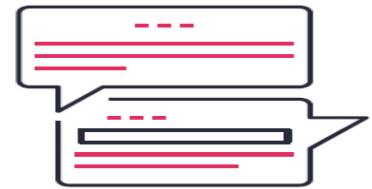

3. REVIEW
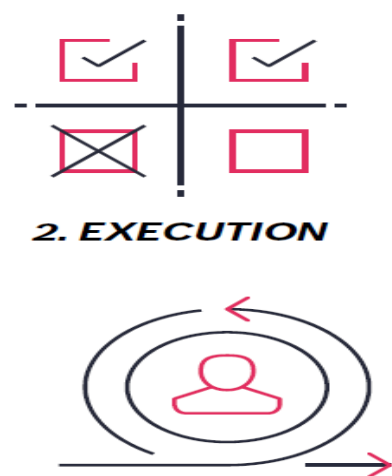

4. RINSE \& REPEAT

Figure 1. The sprint life cycle.

Scrum Theory. Scrum is built upon the principle of empirical process management. Empiricism argues that information arises from experience, relying on what is learned, and makes choices. To maximize predictability and control risk, Scrum employs an iterative, gradual method. Three foundations underpin any empirical process management implementation [8].

1) Transparency

2) Inspection

3) Adaptation

4) The Scrum Team.

The scrum team must be multi-functional and self-organizing. That is, instead of directing teams by others, self-organizing teams choose the best way to get their work done, multifunctional teams have all the competencies needed to get the job done without relying on others who are not part of the team. The Scrum team model is designed to improve creativity, flexibility, and productivity. The 
Scrum team has proven its effectiveness and any complicated work. Scrum Teams offer products frequently, which increases the chances of feedback. Additional deliveries to "Done" guarantee and always provide a potentially useful version of the business product [9]. The Scrum Team consists of:

1) The product owner

2) Development team

3) Scrum Master

4) APM-BIM Integration.

The development in construction methods has become more complex, which made previous knowledge insufficient and the need for a clearer methodology. As complex projects require different treatments to solve problems, the introduction of Building Information Modeling (BIM) models followed by an increasing number of programs, updated file formats, information exchange platforms, and visualization tools regarding linking individual efforts to a central database to improve interactions within team members resulting in greater accuracy Fine detail with less potential for unexpected errors during the construction process. BIM as a technology-driven process made it easy for participating experts to collaborate using a 3D building model to manage data and the efforts associated with 3D digital modeling in developing a data-driven platform is a popular data environment that includes all the information. Graphic and non-normative related to the construction process.

However, there is some kind of inflexibility towards the realities of the business and the ability to adapt continuous feedback from internal and external stakeholders such as the customer and end-user in the construction process that may require the continuous design in a convergent manner with the full participation of the stakeholders. In other words, for such flexibility, the Agile method appears to be much more practical than following the Waterfall Progress method which is a pre-defined and pre-designed method with all the details initially planned, resulting in less flexibility for changes around the world. Also, business needs may change overnight making the speed of the traditional waterfall process insufficient. Moreover, it seemed impossible to define all requirements and details at the outset without any additional upgrades from changes in work or user feedback. Reverse agile management where continuous development takes place at every stage [10].

\section{Field Survey and Statistical Analysis}

After having been answered by 52 participants who participated in the questionnaire, the results will be presented in the form of tables and graphics in order to obtain clarity in analyzing the responses and display the arithmetic mean after finding the frequencies of the response, the responses were sorted into main axes.

The results were as follows:

The first axis: personal data. In order to present the survey results, general information includes:

1) Educational background. The Percentage of respondents according to their academic degree. (51.9\%) have MSc, (40.4\%) have BSc, and (7.7\%) have Ph.D.

2) Engineering specialization. The respondents 'engineering specialization where the highest percentage of civil engineering majors was $(75 \%)$, followed by architecture majors $(5.8 \%)$. The remaining percentage was distributed to the rest of the disciplines

3) Age. The age of the respondents was divided into 4 groups, and the largest percentage was for the group (20-29) years, and the percentage was (30.8\%), followed by the category (30-39), the percentage was $(36.5 \%)$, Then the category $(40-49)$ by $(26.9 \%)$ and finally the category $(50-59)$ by $(5.8 \%)$ 
4) Years of Experience. The respondents 'years of experience were divided into four categories (less than 5 years, 5-10 years, 10-15 years, and more than 15 years), and the percentages were $(38.5,13.5,15.4$, and $32.7 \%)$ respectively.

5) Responder position in his organization. The most specialized participant in the survey is (site engineer, followed by the consultant, academic, site manager, and designer) with proportions $(42.3,30.8,11.5,7.7,3.8 \%)$ respectively.

6) Responder organization work. Figure 2 shows the organization's specialization for respondents. The largest percentage was for contracting institutions (implementing agency) at a rate of $(36.5 \%)$, followed by project management at $(28.8 \%)$, Owner, the supervisor was (11.5\%), Consultant (7.7\%), and Academic (3.8\%).

7) Organization sector. Work in the Organization was divided into three types of respondents (public, private, and both). The public sector is at the highest rate $44.2 \%$, followed by the private sector $40.4 \%$, then both $15.4 \%$. The result showed that the sample contained all work sectors, which indicates that the survey results reflect the nature of the work sectors.

8) Organizations use BIM technologies. The survey on the extent to which Iraqi organizations use BIM techniques indicated that (59.6) of the organizations do not use these technologies, and this may be because they are modern technologies and there is no knowledge of this technology yet.

9) Project Management Knowledge. The survey revealed that the Iraqi engineer has a great knowledge of project management specialization, and the percentage for answering (yes) to the question (Do you have knowledge of project management) was 96\%.

10) Agile Project Management Knowledge. The percentage was $25 \%$ of Agile Project Management Knowledge.

The Second Axis: The positive factors affecting time, quality, and cost. This axis tested 28 questions and showed the effect of each of them on time, cost and quality. Table 2 shows the arithmetic average after using the five-point Likert scale on the importance of the questions on the influence triangle (time, quality, and cost) after analyzing the occurrences of each question and giving a standard weight to each option. Through the initial questionnaire and after combining the similarities of benefits and implementation practices of APM, BIM extracted 28 factors that have a positive effect on time (reduces project time), cost (reduces project cost), and quality (increases project quality), which was the relative importance index more than $80 \%$ these factors, to give a weight to each point.

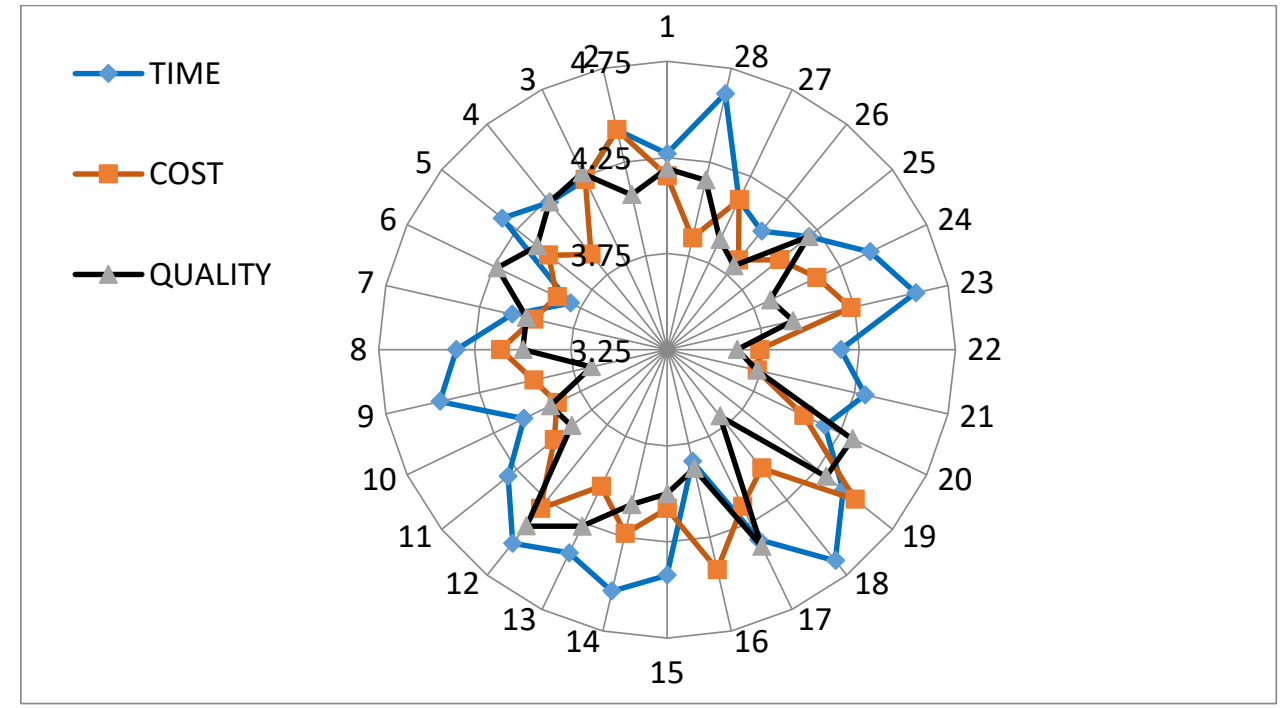

Figure 2. The positive effect of the selected factors on time, cost, and quality. 
The questionnaire asked the respondent to express the importance of each of these 28 factors on each of the time, cost, and quality individually and the extent of the impact was from 5 categories (very influential, influential, average effect, non-influential, and Very non-influential) and the weight of the very influencer was 5 and the weight of very ineffective was 1 . The arithmetic mean of all results was extracted for each axis separately [11]. Table 2 shows the positively influencing factors and the arithmetic average and the sequence of questions received appears in Figure 2.

Table 2. The arithmetic means for positive factors.

\begin{tabular}{|c|c|c|c|c|}
\hline $\mathbf{S}$ & Factor & Time & Cost & Quality \\
\hline 1 & Automatic connection between all disciplines electronically in BIM technologies & 4.27 & 4.15 & 4.19 \\
\hline 2 & BIM technologies discover design errors and their intersections before construction. & 4.42 & 4.42 & 4.08 \\
\hline 3 & BIM facility to follow work progress. & 4.23 & 4.23 & 4.27 \\
\hline 4 & BIM ensures work according to the planned design & 4.23 & 3.88 & 4.23 \\
\hline 5 & BIM improves facility management and maintenance. & 4.35 & 4.04 & 4.12 \\
\hline 6 & BIM helps in implementing sustainable requirements & 3.81 & 3.88 & 4.23 \\
\hline 7 & Using BIM will reduce change orders & 4.08 & 3.96 & 4.00 \\
\hline 8 & $\begin{array}{l}\text { The status of project progress must be visible, and a ratio and weight to each phase } \\
\text { should be placed }\end{array}$ & 4.35 & 4.12 & 4.00 \\
\hline 9 & $\begin{array}{l}\text { Work teams and management must meet, and the work is divided according to the } \\
\text { order of priority for the value of work. }\end{array}$ & 4.46 & 3.96 & 3.65 \\
\hline 10 & Emphasis on business value & 4.08 & 3.88 & 3.92 \\
\hline 11 & $\begin{array}{l}\text { At the beginning of each stage, the paragraphs should be clarified (not achieved, in } \\
\text { progress, verification of achievement, done.) }\end{array}$ & 4.31 & 4.00 & 3.88 \\
\hline 12 & Improved planning systems have a positive effect & 4.54 & 4.31 & 4.42 \\
\hline 13 & Improved control systems have a positive effect & 4.42 & 4.04 & 4.27 \\
\hline 14 & Improving coordination and communication between stakeholders & 4.54 & 4.23 & 4.08 \\
\hline 15 & Reducing project time through BIM techniques & 4.42 & 4.08 & 4.00 \\
\hline 16 & BIM technologies and programs reduce the gap between cost estimate and reality & 3.85 & 4.42 & 3.88 \\
\hline 17 & Provide the staff with the delivery details as the requirements of the project owner & 4.35 & 4.15 & 4.38 \\
\hline 18 & Provide the staff with delivery details, such as the required date for delivery & 4.65 & 4.04 & 3.69 \\
\hline 19 & $\begin{array}{l}\text { If the inspector decides to reject a part of the work, he must adapt and make the } \\
\text { necessary amendment }\end{array}$ & 4.42 & 4.50 & 4.31 \\
\hline 20 & Agile application leads to improved quality & 4.16 & 4.04 & 4.32 \\
\hline 21 & Agile application facilitates monitoring of work progress & 4.31 & 3.73 & 3.73 \\
\hline 22 & Agile application leads to the early and expected delivery of the project & 4.15 & 3.73 & 3.62 \\
\hline 23 & Agile approach helps reduce schedule & 4.58 & 4.23 & 3.92 \\
\hline 24 & The necessity to allow change (flexibility) & 4.42 & 4.12 & 3.85 \\
\hline 25 & Agile approach promotes creativity and innovation & 4.19 & 4.00 & 4.19 \\
\hline 26 & $\begin{array}{l}\text { In the agile approach, developers should receive feedback frequently at the end of each } \\
\text { stage of the work }\end{array}$ & 4.04 & 3.85 & 3.81 \\
\hline 27 & $\begin{array}{l}\text { Owners participate in expressing their requirements at the end of each stage, but they } \\
\text { are not allowed to interfere in daily activities }\end{array}$ & 4.12 & 4.12 & 3.88 \\
\hline 28 & $\begin{array}{l}\text { Frequency of daily meeting These meetings are often held standing. To guarantee it is } \\
\text { short and straightforward }\end{array}$ & 4.62 & 3.85 & 4.15 \\
\hline
\end{tabular}

The Third Axis: The negative impact of the difficulties of implementing BIM and Agile and the integration between them in the management of construction projects. Through the initial questionnaire and after combining the similarities between the difficulties of APM, BIM has a negative effect on time (increases project time), cost (increases project cost) and quality (reduces project quality), relative importance index more than $50 \%$ of these factors, to give weight to each point. The questionnaire asked the respondent to express the importance of each of these 8 factors in 
each of the time, cost, and quality separately. The same method was used. The arithmetic mean of all results was extracted for each axis separately, and this is shown in Table 3.

Table 3. The arithmetic means for negative factors.

\begin{tabular}{|c|l|c|c|c|}
\hline $\mathbf{S}$ & \multicolumn{1}{|c|}{ Factor } & Time & Cost & Quality \\
\hline 1 & $\begin{array}{l}\text { Companies' believe that they have current software that is sufficient for them to adopt new } \\
\text { technologies }\end{array}$ & 4.23 & 4.23 & 4.15 \\
\hline 2 & Lack of training for employees on BIM techniques & 4.27 & 4.04 & 4.12 \\
\hline 3 & Lack of knowledge of BIM techniques & 4.27 & 3.92 & 4.08 \\
\hline 4 & Lack of government legislations related to BIM and Agile technologies & 3.96 & 3.88 & 4.00 \\
\hline 5 & Difficulty changing the behavior of the organization's management & 4.12 & 4.04 & 4.23 \\
\hline 6 & Lack of dedicated multi-functional teams to implement BIM and Agile integration & 4.12 & 3.85 & 4.08 \\
\hline 7 & The absence of real projects to which agile management has been applied & 3.92 & 3.92 & 4.23 \\
\hline 8 & The absence of a request from the customer to implement BIM and Agile integration & 3.88 & 4.12 & 3.92 \\
\hline
\end{tabular}

Figure 3 shows the negative influencing factors and the arithmetic average of the expert's response regarding the effect of the factors on time, cost and quality, and illustrates the sequence of questions listed in Table 3.

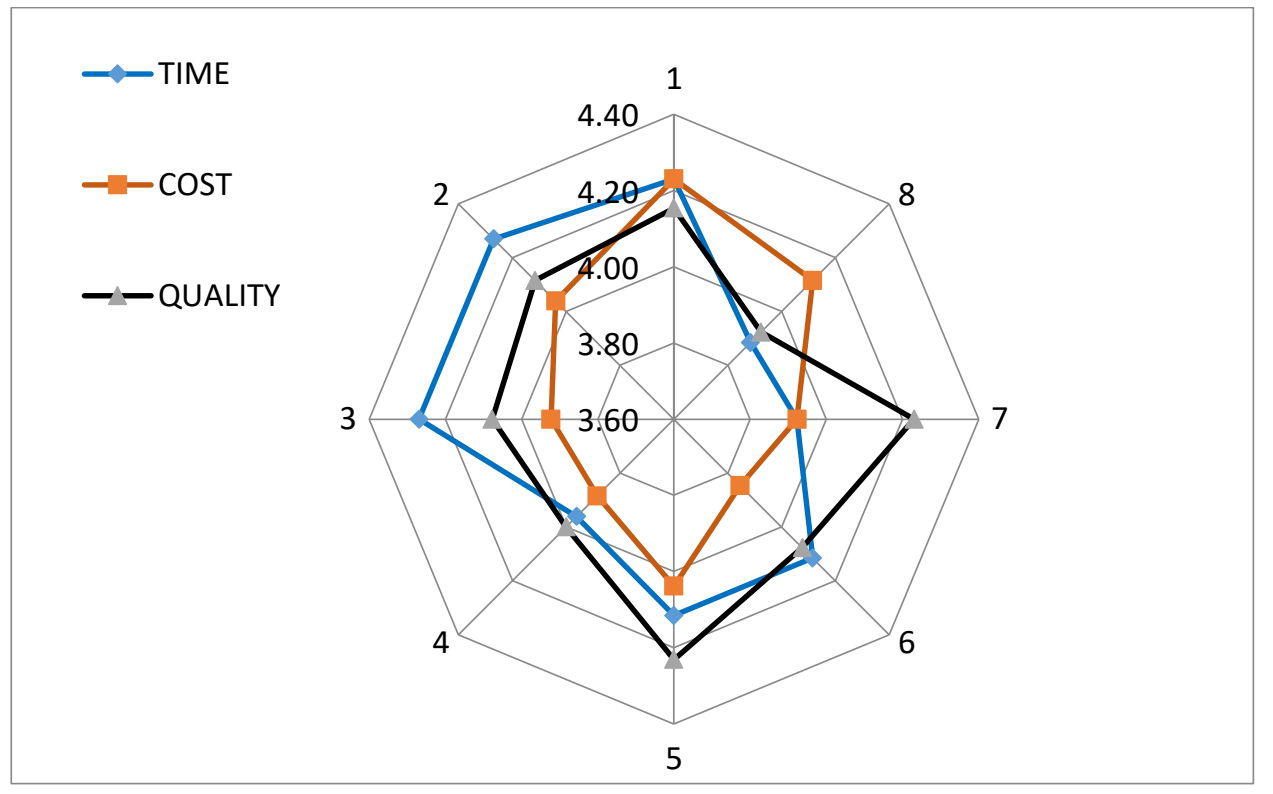

Figure 3. The negative effect of the selected factors on time, cost, and quality.

\section{Conclusions}

This article is the first of its kind to focus on the common interests of BIM technology and the Agile methodology in Iraq and places the targeted combination between the two within these common interests. The researcher reviewed the literary part of Agile and BIM separately to gain a comprehensive understanding of each, after which the main common interests between them were summarized framework and revised to fit the same. The most important possible benefits when applying integration between BIM and APM were discussed, as well as the potential difficulties and the extent of the impact of these factors on the time, quality, and cost of projects. The researcher concluded the following

- The age group (20-40) years in the construction sector has a presence of up to $70 \%$ and this is one of the positive points for adopting modern technologies (such as BIM, Agile) that the youth group can change and adapt quickly. 
- The private sector in Iraq is less compared to the public sector, and this forces the government to adopt mechanisms that activate the private sector to reduce the burden on the public sector and reduce the unemployment rate for engineers and other specializations.

- Most of the organizations in the Iraqi construction industry do not use BIM technology, and this necessitates adopting a new policy in order to spread the culture of using BIM.

- The field survey confirmed that the benefits of adopting BIM and the generation methodology are many and valuable, and this is what was explained in Chapter Three.

- The best feature of agile and BIM integration that gives the best positive effect on time, quality, and the cost is to improve planning, and this is what the field survey proved.

- Through the field survey, it was found that the belief of companies, organizations, and institutions that they have sufficient current programs to adopt new technologies is the most negatively affecting the time, cost, and quality of projects.

\section{References}

[1] S. Muhammed, Assessing economical aspects of sustainable buildings design using BIM, M.Sc. thesis, University of Baghdad, 2018.

[2] Y. Arayici, J. Counsell, L. Mahdjoubi, G. A. Nagy, S. Hawas, and K. Dweidar, K. eds., Heritage building information modelling. Taylor \& Francis, 2017.

[3] T. Kouider, P. Sykes, and M. Hamma-Adama, BIM manager, coordinator, consultant, analyst..., what does a confused AEC industry need?. Proceedings of the 8th International Congress on architectural technology (ICAT 2019), 2019, PP. 67-88.

[4] M. John, J. Messner, and R. Kreider, R., BIM planning guide for facility owners. Pennsylvania State Univ., University Park, PA, 2013.

[5] M. A. Abdulkarim, Team work and tasks. Arabia BIM Journal, 5, 2016 (In Arabic).

[6] S. K. Sojan and A. Ajayakumar, Agile management in construction industry. International Research Journal of Engineering and Technology (IRJET), 6, pp. 5128-5134 (2019).

[7] E. Taymor, Agile handbook. (2017).

[8] Y. C. Liu, Scrum in construction industry to improve project performance in design phase. Harrisburg University of Science and Technology. Available at: http://digitalcommons.harrisburgu.edu/pmgt_dandt/31\%0AThis (2018).

[9] M. James and L. Walter, Scrum reference card - A management framework. CollabNet, Inc, p. 6. Available at: https://www.collab.net/sites/default/files/uploads/CollabNet_scrumreferencecard.pdf (2017).

[10] O. Salim, BIM and mangement. Arabia BIM Journal, 33, p. 56, 2019 (In Arabic).

[11] M. W. Jumaah and M. Altaie, Application of nanotechnology in Iraqi construction projects. IOP Conference Series: Materials Science and Engineering, 901(1). doi: 10.1088/1757899X/901/1/012019 (2020). 